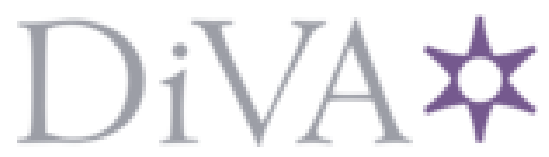

http://www.diva-portal.org

This is the published version of a paper published in Ergonomics in design.

Citation for the original published paper (version of record):

Glimskär, B., Lundberg, S. (2013)

Barriers to Adoption of Ergonomic Innovations in the Construction Industry.

Ergonomics in design, 21(26): 26-30

http://dx.doi.org/10.1177/1064804613488890

Access to the published version may require subscription.

N.B. When citing this work, cite the original published paper.

Permanent link to this version:

http://urn.kb.se/resolve?urn=urn:nbn:se:kth:diva-156885 


\section{Ergonomics in Design: The Quarterly of Human Factors Applications \\ http://erg.sagepub.com/}

\section{Barriers to Adoption of Ergonomic Innovations in the Construction Industry \\ Bo Glimskär and Stefan Lundberg \\ Ergonomics in Design: The Quarterly of Human Factors Applications 2013 21: 26}

DOI: $10.1177 / 1064804613488890$

The online version of this article can be found at:

http://erg.sagepub.com/content/21/4/26

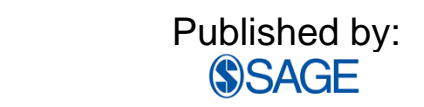

http://www.sagepublications.com

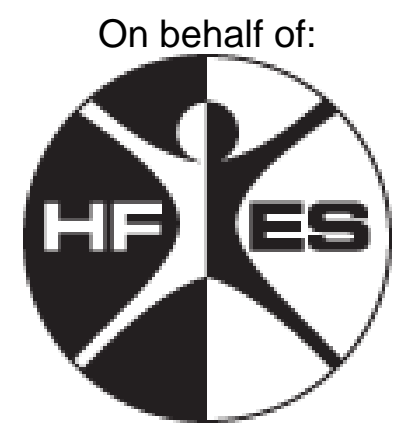

Human Factors and Ergonomics Society

Additional services and information for Ergonomics in Design: The Quarterly of Human Factors Applications can be found at:

Email Alerts: http://erg.sagepub.com/cgi/alerts

Subscriptions: http://erg.sagepub.com/subscriptions

Reprints: http://www.sagepub.com/journalsReprints.nav

Permissions: http://www.sagepub.com/journalsPermissions.nav

Citations: http://erg.sagepub.com/content/21/4/26.refs.html

>> Version of Record - Oct 25, 2013

What is This? 


\title{
Barriers to Adoption of Ergonomic Innovations in the Construction Industry
}

\author{
By Bo Glimskär \& Stefan Lundberg
}

\author{
FEATURE AT A GLANCE: \\ More work-related injuries \\ and problems occur in the \\ construction industry than in \\ other industries, particularly \\ with regard to musculoskeletal \\ disorders. One reason might be \\ that the industry is organized \\ around projects that lead to \\ short-term benefits and does \\ not stimulate innovations that \\ will reduce injuries in the future. \\ In this article, we present \\ the findings from a survey \\ performed in Sweden among \\ 50 floor-laying companies. The \\ results indicate that short-term \\ income revenues override \\ concerns over the long-term \\ risks of injuries and employees \\ leaving the profession as a \\ result of those injuries.
}

\section{KEYWORDS:}

occupational injury, ergonomics, working tools, injury risk, musculoskeletal disorders

\section{THE CONSTRUCTION INDUSTRY AND WORK-RELATED INJURIES}

The construction industry is overrepresented compared with other industries in terms of work-related injury problems, particularly musculoskeletal disorders (MSDs). To illustrate, a 1987 survey involving 12 U.S. states showed that occupational back injury was the most frequently reported work-related disorder, accounting for $22 \%$ of all reported cases and $32 \%$ of all workers' compensation dollars (Bureau of Labor Statistics, 1995). In another report (Bernold, Lorenc, \& Davis, 2001), during the period 1980 to 1990, workers' compensation benefits increased by $157 \%$ and employer costs rose by $143 \%$ (Nelson, 1993).

Studies of how people relate to the risk of occupational injury indicate a tendency to underestimate the risk at work compared with other risks in society. Most people are aware of the potential for traumatic injury and are willing to prevent such injuries, but they consider the risk of an occupational accident caused by poor work methods to be low (Larsson, 1996, 1998). Consequently, such injuries are not a priority for prevention. The interest in ergonomic tools that reduce the long-term risk of disability is rather low, and it takes more than just an ergonomic improvement to change the way that work is done.

\section{TOOLS THAT WORK}

In the Swedish construction industry during the 1970s and 1980s, many initiatives were undertaken to develop new tools and work methods to prevent occupational injuries, and one of the authors (Glimskär) was deeply involved in several of those initiatives. Although numerous ergonomic tools were
The desire for short-term savings may be the reason some construction companies do not use tools that protect workers against repetitive strain injury.

developed and offered to the market, only a few have had any major impact.

One example of such a tool is an overhead drill stand, which was developed to reduce injuries caused by working with heavy loads with the arms over the head (E. Andersson, 1983). The overhead drill stand facilitates the otherwise heavy job of operating chiseling and drilling machines when working on walls and ceilings (Figure 1). The stand raises and lowers the machine automatically during the job, and it also supplies a bit force for drilling holes in ceilings. Production studies have shown that using the stand reduces the physiological work strain to an acceptable level and enables the work to be done more efficiently than before.

This product is so simple that anyone can use it without any training. The product has been marketed in a traditional way with leaflets and through notice boards on TV, by direct mail, and by offering free loans of the product. Despite sales of several thousand units, this aid has not achieved a total breakthrough and become adopted as standard equipment. The reason is that it is considered too cumbersome to take to a job site despite the benefits derived from using it.

One way to reduce strain from work performed above shoulder height could be to prepare embedded hardware that enables the fastening en masse of installations in tight spaces, such as conduit runs. In addition to reducing the amount of effort in work performed above shoulder level, this solution also saves money in production. In this case, the ergonomically improved work method has been met with resistance both because it takes more planning and, more important, because of how workers are paid. Fitters and installers are relatively well compensated for 


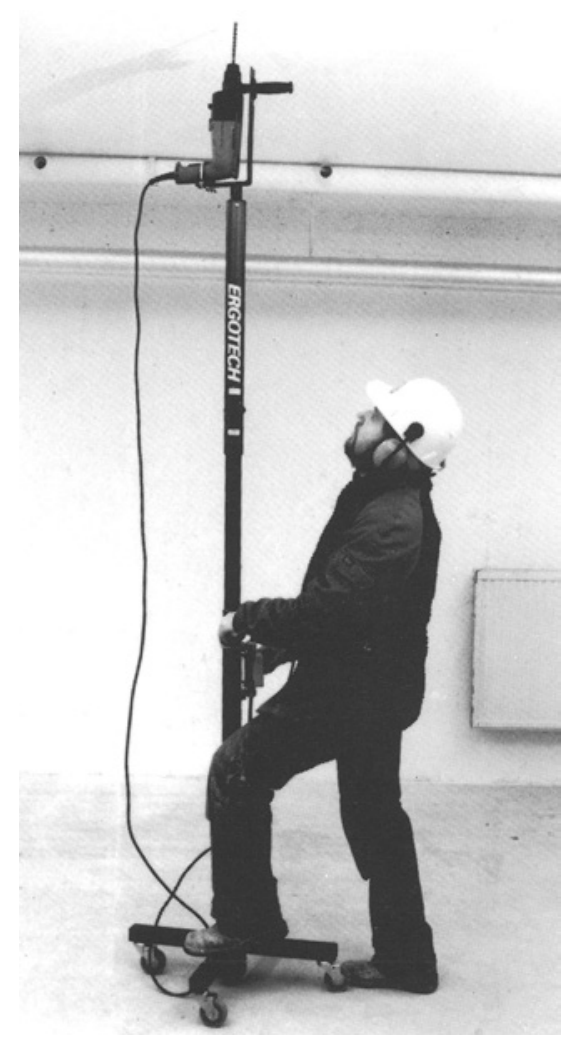

Figure 1. An overhead drill stand (photo by Dan Nilsson).

doing overhead work and are not interested in a lower income (Rose \& Glimskär, 1994).

\section{THE FLOOR-LAYING INDUSTRY}

Floor-laying is a well-delimited industry with well-known problems. Half of all floor layers experience knee problems with a frequency ranging from occasional to daily, and many will not be able to work until retirement age in this profession (Jensen \& Friche, 2010). The Swedish Foundation for Industrial Safety and Health in the Construction Industry began mapping floor layers' work conditions as early as 1982 by studying 45 work sites and sending 500 questionnaires to floor layers ( $\AA$. Andersson, 1983).

The results of the 1982 survey showed that work environment problems fell into two main areas: an ergonomic one, including work postures and heavy lifting, and chemical health risks. As a consequence of these problems, use of chemicals decreased, but the work methods did not change, which is still reflected in injury statistics in Sweden.

Initiatives were taken in 1990 to change floor layers' work methods. At construction sites, participatory groups were organized with the primary purpose to create new tools to solve production problems and to improve work postures for floor layers. One such tool was based on a telescoping pole that made it possible to spend $40 \%$ instead of $70 \%$ of time working in a kneeling position (Figure 2). The tool is rather

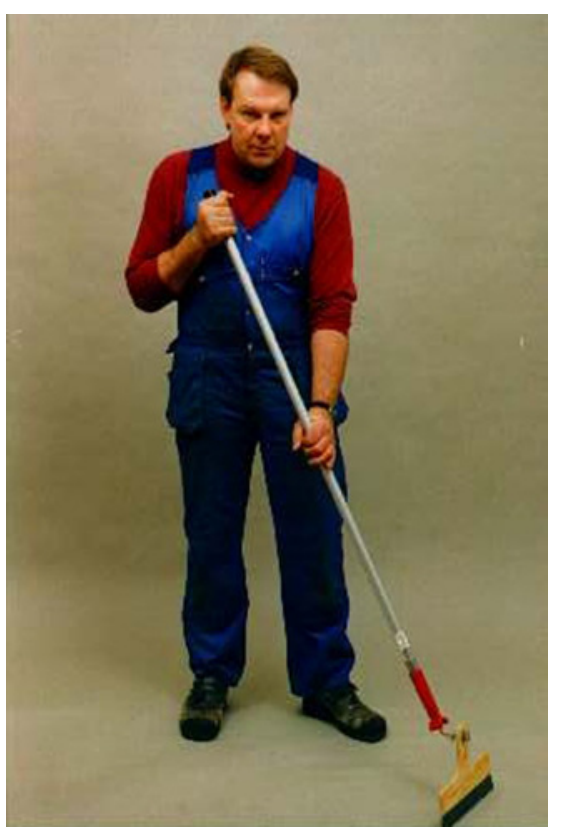

Figure 2. Spreading glue with a telescoping pole (photo by Dan Nilsson).

simple and involves basically the same extension handle that painters use for a roller.

Different communication methods were used to encourage the floor layers to use this tool, including education, a cartoon (Figure 3), and theatrical performances. A great deal of effort was put into this trial, and at most, about $30 \%$ of the floor layers used it (Rygh \& Nielsen, 1991).

Since 1996, the trade union and employers' association in Denmark have tried to persuade floor layers to do their work standing up. But a survey in Denmark in 1999 showed that only $13 \%$ of the floor layers had tried the new tool. Since then, new and improved tools that make it possible to carry out an array of tasks have been introduced, such as gluing, welding, and cutting. In 2002 (Jensen \& Kofoed, 2002), it was decided to try to make the telescoping pole the first choice of floor layers, and a massive educational project began. In Denmark, this project resulted in a much more positive attitude toward working while standing, but the project leaders were concerned about what would happen when and if strong support from the union was withdrawn.

\section{WHAT HAS HAPPENED SINCE 1990?}

We studied the attitudes among floor layers in Sweden with regard to use of the telescoping pole 20 years after its introduction by mailing a questionnaire to a representative selection of floor-laying companies. Through this research we also could implicitly study management support for this method.

Companies were selected with input from the Swedish Flooring Trade Association. Of a total of 278 companies in Sweden, 50 were selected randomly, and representatives 


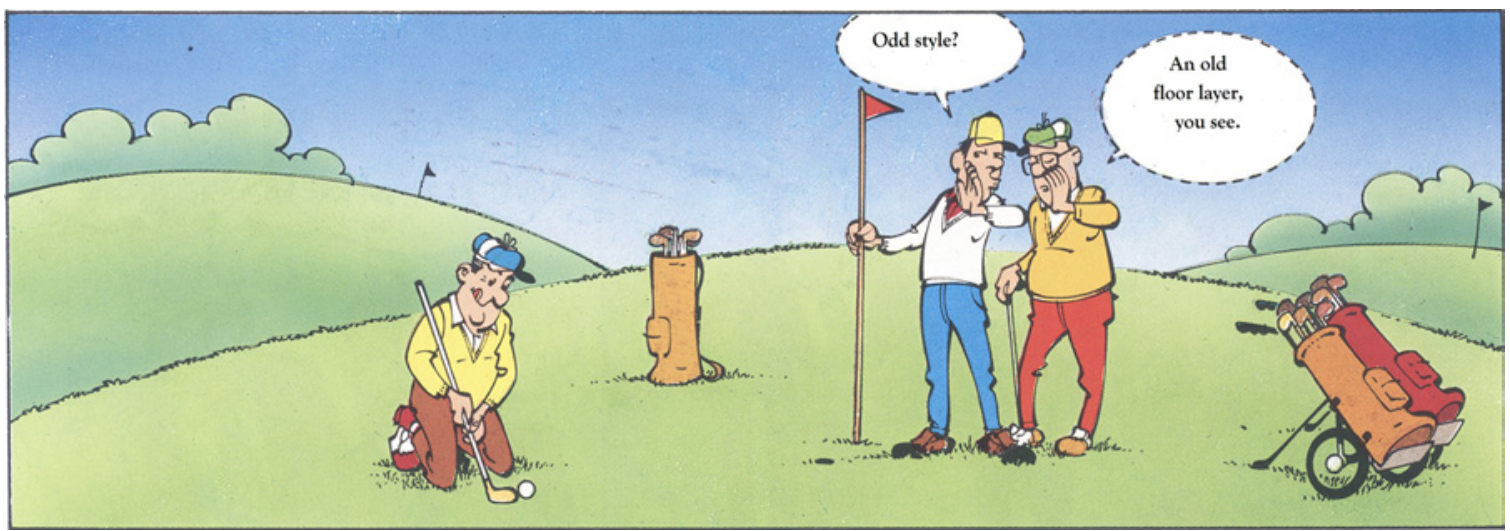

Figure 3. Cartoon used to encourage floor layers to use the telescoping pole.

\begin{tabular}{|c|c|c|c|}
\hline Category & Frequency & Missing & Valid Answers \\
\hline Small (1-3) & 8 & 2 & 6 \\
\hline Medium (4-20) & 35 & 2 & 33 \\
\hline Large $(\rightarrow 20)$ & 7 & 2 & 5 \\
\hline$n$ & 50 & 6 & 44 \\
\hline
\end{tabular}

a. Number of employees in the company.

from 44 of them completed the questionnaire (Table 1). The respondents were divided into three categories: small companies, with 1 to 3 employees; medium-sized companies, with 4 to 20 employees; and bigger companies, with more than 20 employees. This categorization helped us determine if there are any differences between companies of different sizes.

If the selected company representative did not answer the questionnaire within 2 weeks, we sent a reminder. If there was still no answer, the company was regarded as a dropout and a missing answer.

\section{COMPANY SIZE GOVERNS THE USE OF ERGONOMIC TOOLS}

Among the valid answers, almost all of the 44 companies had tried the tool at different times, but only 14 actually used it, mainly on floor areas exceeding 100 square meters. A majority of the small and medium-sized companies never used the tool. Users were found among the large companies and some of the medium-sized companies (Figure 4).

As can be seen, company size is related to use of the tool. One reason not to use the tool is the size of the job. With the tool, about one third of the work can be done in a standing position, but the rest of the work has to be done in a kneeling

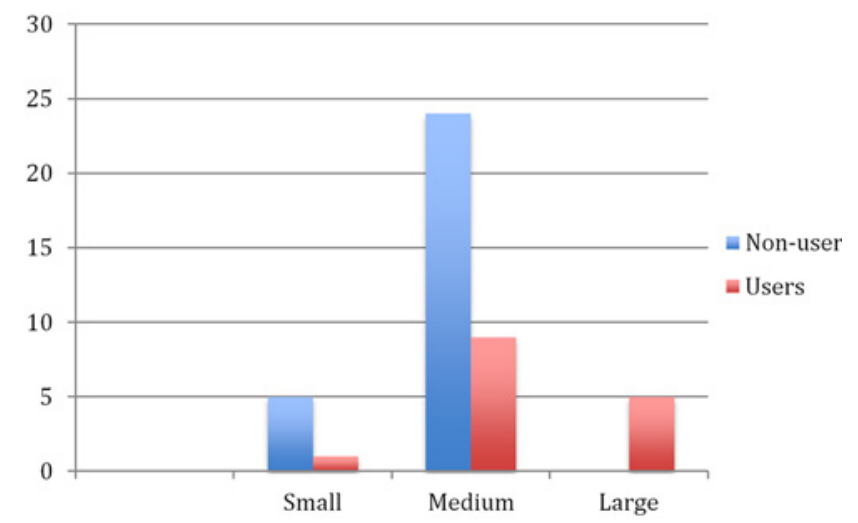

Figure 4. User and nonusers by company size (number).

position. At small jobs, the tool was not considered to be of much help; a worker replacing vinyl in a small bathroom, for example, still has to bend down on his or her knees and do the fitting and cutting.

One might think that the quality of work is the main problem, but this does not seem to be an issue. Companies' survey responses show that quality of gluing was assessed to be the same while standing as while kneeling. Among the nonusers, nearly half of them said the result was worse, and just a fifth thought it would result in the same quality as if the work were done while kneeling (Figure 5). Of 29 companies, 10 reported not knowing what quality they would get by spreading the glue while standing.

It is workers at the small companies who are not comfortable with the quality (Figure 5). The respondents from medium-sized companies are almost equally in favor compared with those who are against the tool. Again, the kind of job the companies are involved in matters.

How do the companies' representatives appreciate the relation between wear-and-tear injuries and use of a tool that could reduce such injuries? Nearly two thirds of respondents 
fea ture | Barriers to Adoption of Ergonomic Innovations in the Construction Industry

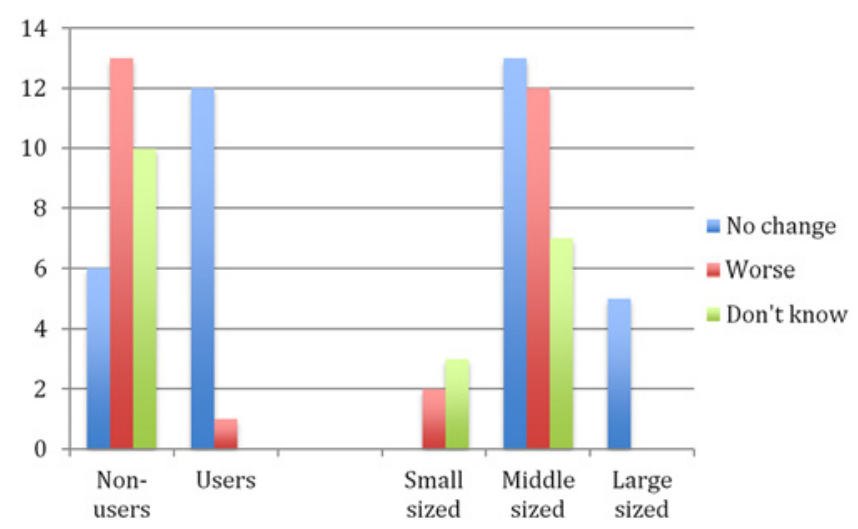

Figure 5. How quality is affected by using the new tool, by users and nonusers, respectively, by company size.

said they did not have any problems with the floor layer's knees. At the same time, 22 of them admitted that they have employees with knee problems. Given the statistics, it is obvious that there is a high risk of future disabilities for workers in this profession.

\section{REASONS FOR NOT USING WELL-DESIGNED TOOLS}

The majority of survey respondents said that they did not want to change the way they work because it takes time to learn how to do things in a new way. Respondents at 7 of 10 companies reported that their colleagues do not use the tool. Even greater numbers said that the work cannot be done fast enough with the tool. When asked how much faster the work must be done to change a work method, the majority answered, "The same speed." Still, respondents from 16 companies claimed a need for improved productivity of $25 \%$ to $50 \%$, as shown in Figure 6.

\section{CONCLUSION}

In our study, respondents at the companies that were using the tool said that neither quality nor speed was affected negatively by using the tool. They even said that the work was done faster with the tool than without it. The Danish study (Jensen \& Kofoed, 2002) arrived at the same conclusion. But knee injuries are not an issue that worries company managers. In another Danish study, the same research team reported that "the risk was at least double for serious knee complaints among floor layers who had not used the new working methods" (Jensen \& Friche, 2010, p. 615). In fact, floor layers themselves confirmed in the Danish study that use of the tool reduced the problems they experienced with both knees and lower-back injuries.

Floor layers may not be aware of the relation between work methods and future repetitive strain injuries, though such injuries could make it impossible for them to work until they are

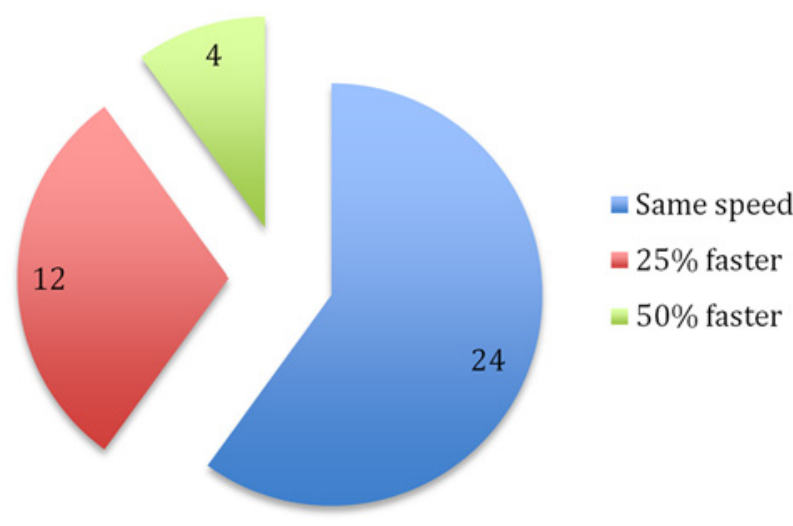

Figure 6. How much faster must the work be done in order to use the tool?

eligible for a pension. For the entire group, the relation between injuries and floor laying is strong if one looks at the outcome of notified injuries over the years. The fact that respondents at 16 of 44 companies said that the work must be done much faster to justify changing tools and work methods reveals their low priority for the long-term health of employees. Getting companies to invest in ergonomic improvements also requires that such improvements result in productivity improvements and time savings so that the time needed to recoup the investment is short. The investment involved in moving from one work method to another is not recovered in the short term and, in fact, may never be recovered, depending on whether the company has to hire new workers if the old workforce is worn out.

Our results confirm the impression that a worker's health is not a priority for many companies in the construction business. This finding calls for instruments to persuade construction companies to calculate future occupational injuries as a cost. Perhaps the workers' compensation insurance fees should be adjusted based on the company rather than the trade. If a company is working with methods that reduce ergonomic risks, lower insurance fees could compensate them. This structure would improve the willingness to work with preventive measures.

Further studies should focus on determining, with all other variables being the same, the scope and size of the increased employee benefit from an ergonomically improved work environment that are required before the innovation or improvement will be fully adopted.

\section{REFERENCES}

Andersson, Å. (1983). Kartläggning av golvbranschens arbetsmiliö [The flooring industry's work environment survey]. Danderyd, Sweden: Bygghälsans forskningsstift (BHF).

Andersson, E. R. (1983). Maskinstöd för handhållna bilningsmaskiner och borrhammare [Tool support for chiseling and drilling equipment]. Stockholm, Sweden: Trita-BEL, 0349-0890; 0017 KTH. 
f e a t u r e | Barriers to Adoption of Ergonomic Innovations in the Construction Industry

Bernold, L. E., Lorenc, S. J., \& Davis, M. L. (2001). Technological intervention to eliminate back injury risks for nailing. Journal of Construction Engineering and Management, 127, 245-250.

Bureau of Labor Statistics. (1995). Workplace injuries and illnesses in 1994 (USDL-95-508). U.S. Department of Labor, Federal Register (August 3, 1992).

Jensen, L. K., \& Friche, C. (2010). Implementation of new working methods in the floor-laying trade: Long-term effects on knee load and knee complaints. American Journal of Industrial Medicine, 53, 615-627.

Jensen, L. K., \& Kofoed, L. B. (2002). Musculoskeletal disorders among floor layers: Is prevention possible? Applied Occupational and Environmental Hygiene, 17, 797-806.

Larsson, T. J. (1996). Upplevda risker för sjukdom och olycksfall 1986: Attityder hos förvärvsarbetande svenskar med kroppsarbete [Experiences of risks for occupational injuries and accidents 1986: Swedish manual workers' attitudes]. IPSO FACTUM 6.

Larsson, T. J. (1998). Decision making in relation to occupational health and safety among small business: A survey of 100 small business owners/managers in Victoria. Victoria, Australia: Victorian WorkCover Authority.

Nelson,W. J. (1993). Workers compensation: Coverage, benefits, and costs, 1992. Social Security Bulletin, 56(3), 68-74.

Rose, L., \& Glimskär, B. (1994). Arbete över axelhöjd: Kartläggning och förslag till förändringar. Sammanfattning [Work above shoulder height: Survey and ideas for alterations. Summary]. Stockholm, Sweden: Arbetsmiljöfonden.

Rygh, S.-A.., \& Nielsen, C. (1991). Golvläggarprojektet: Utveckling av golvläggares totala arbetsmetodik [Floor layer project: Development of floor layers' work methods]. Stockholm, Sweden: Belab.

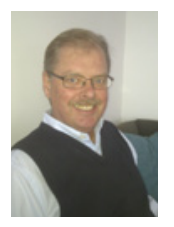

Bo Glimskär is a PhD student at the Center for Health and Building at KTH, the Royal Institute of Technology, in Stockholm, Sweden. He is a human factors specialist with 30 years of experience in product design for the construction industry, as a director at a construction ergonomic laboratory (Belab). He received an MS in civil engineering from KTH.

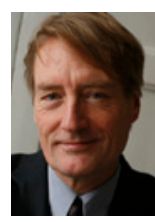

Stefan Lundberg, PhD, is a civil engineer at the Centre for Health and Building and a researcher and associate professor at KTH, the Royal Institute of Technology, in Stockholm, Sweden. His research mainly concerns assistive technology supporting older adults' aging in place. He is also involved in ergonomic design regarding the interaction between people with Alzheimer's disease and assistive technology. He works in the field of applied technology.

\section{elid}

Copyright 2013 by Human Factors and Ergonomics Society. All rights reserved. DOI: $10.1177 / 1064804613488890$ 